Annals of International Medical and Dental Research

E-ISSN: 2395-2822 | P-ISSN: 2395-2814

Vol-8, Issue-1 | January-February 2022

DOI: $10.53339 /$ aimdr.2022.8.1.24

Page no- 180-184 | Section- Research Article (Anatomy)

\title{
Anatomical Variations of Profunda Femoris Artery in Indian Population
}

\author{
Santosh Vaman Waghmode1, Sadiqali Abbasali Syed ${ }^{2 *}$
}

\begin{abstract}
${ }^{1}$ Assistant Professor, Department of Anatomy, Government Medical College, Miraj, Maharashtra, India. Email: officialsurya24by7@gmail.com Orcid ID: 0000-0002-4112-2122

2Assistant Professor, Department of Anatomy, Government Medical College, Miraj, Maharashtra, India. Email: sadiqalisyed23@gmail.com Orcid ID: 0000-0002-4281-6839

${ }^{*}$ Corresponding author
\end{abstract}

\section{Received: 30 July 2021}

Revised: 30 September 2021

Accepted: 12 November 2021

Published: 22 December 2021

\begin{abstract}
Background: Aim: To assess anatomical variations of profunda femoris artery in Indian population. Methods: 45 embalmed lower extremities adult human cadavers age range of 30-65 years were recruited for the study. The femoral triangles were dissected with proper care to identify the profunda femoris and circumflex femoral arteries. Their source of origin, position, and distance were noted with the mid-inguinal point (MIP) as a reference point. Results: Side of profunda femoris artery (PFA) was postero- lateral in 60\%, posterior in $30 \%$, lateral in 5\% and absent in 5\%. Medial circumflex femoral artery (MCFA) had $65 \%, 15 \%, 12 \%$ and $8 \%$ and lateral circumflex femoral artery (LCFA) had $80 \%$, $15 \%, 5 \%$ and $0 \%$ respectively. Origin of profunda femoris artery (PFA) was FA in $90 \%$ and common trunk with medial circumflex femoral artery in $10 \%$. Origin of Medial circumflex femoral artery (MCFA) was FA in 55\%, PFA in $40 \%$ and FA with common trunk with MCFA in 5\%. Origin of lateral circumflex femoral artery (LCFA) was femoral artery in 70\%, PFA in $20 \%$ and FA with common trunk with PFA in $10 \%$. A significant difference was observed $(\mathrm{P}<$ 0.05). Conclusions: A thorough knowledge of variation of profunda femoral artery is of great importance and to avoid complications.
\end{abstract}

Keywords:- Profunda Femoral Artery, Medial Circumflex Femoral Artery, Lateral Circumflex Femoral Artery.

\section{INTRODUCTION}

The profunda femoral artery has an important compensatory role for the collateral blood flow in the atherosclerotic occlusive disease through collateral pathways in the lower pelvis, starting from the internal iliac arteries (or the mesenteric arteries if the internal iliac arteries are also affected). ${ }^{[1,2]}$ This collateral pathway is more important if aorto - iliac lesions are associated with femoro - popliteal lesions. ${ }^{[3,4]}$

The common femoral artery (CFA) which is frequently accessed by radiologist and surgeons, is easily accessible to catherization. [5] Knowledge of the anatomy and possible variations of the PFA, LCFA and MCFA are important for clinicians. The PFA is used for arteriography, ultrasound and Doppler imaging, digital subtraction angiography and magnetic resonance imaging.[6] Some of the current uses of the PFA include the use for haemodialysis where it supplants the use of the SFA. The branches of PFA are also used as long vascular pedicle during breast reconstruction after mastectomy in cases of carcinoma of breast. $[7,8,9]$

Bergman et al. describe that various vessel of the profunda complex may more or less dissociate, one or another of them having an independent origin from the femoral artery; 
Annals of International Medical and Dental Research

E-ISSN: 2395-2822 | P-ISSN: 2395-2814

Vol-8, Issue-1 | January-February 2022

DOI: 10.53339 /aimdr.2022.8.1.24

Page no- 180-184 | Section- Research Article (Anatomy)

this may occur to such an extent that a profunda femoris as a definite vessel may not exist. Differing patterns of the origin of the PFA and its branches have been described on a racial basis as well as variations being noted between the two legs of the same individual.[10,11] Points of origin are helpful to avoid high or low punctures. High punctures, above the inguinal ligament, may result in a retroperitoneal hematoma, as the artery is difficult to compress without the support of the femoral head. Low punctures may result in pseudo - aneurysms formation. The present study was conducted to assess anatomical variations of profunda femoris artery in Indian population.

\section{MATERIAL AND METHODS}

A total of 45 embalmed lower extremities adult human cadavers age range of 50 - 85 years, were recruited for the study. The study was started with the approval of institutional ethical review committee.

The skin overlying the anterior compartment of the thigh was incised, dissected and reflected medially. The subcutaneous fat, translucent fascia and superficial vessels were fully dissected and the sartorius muscle and quadriceps muscle identified. The sartorius muscle and the rectus femoris muscle were transacted, to further expose the CFA, SFA, PFA and the LCFA. Femoral triangles were dissected with proper care to identify the profunda femoris and circumflex femoral arteries. Their source of origin and position were recorded. After recording all the parameters, statistical analysis was carried out using Mann Whitney $U$ test. Level of significance was set below 0.05 .

\section{RESULTS}

Side of profunda femoris artery (PFA) was postero- lateral in $60 \%$, posterior in $30 \%$, lateral in $5 \%$ and absent in 5\%. Medial circumflex femoral artery (MCFA) had 65\%, 15\%, 12\% and $8 \%$ and lateral circumflex femoral artery (LCFA) had $80 \%, 15 \%, 5 \%$ and $0 \%$ respectively. A significant difference was observed $(P<0.05)$ [Table 1, Figure 1].

Origin of profunda femoris artery (PFA) was FA in $90 \%$ and common trunk with medial circumflex femoral artery in $10 \%$. Origin of Medial circumflex femoral artery (MCFA) was FA in $55 \%$, PFA in $40 \%$ and FA with common trunk with MCFA in 5\%. Origin of lateral circumflex femoral artery (LCFA) was femoral artery in $70 \%$, PFA in $20 \%$ and FA with common trunk with PFA in $10 \%$. A significant difference was observed $(\mathrm{P}<0.05)$ [Table 2].

Table 1: Variations of profunda femoris artery and its branches.

\begin{tabular}{|l|l|l|l|l|}
\hline Side & $\begin{array}{l}\text { Profunda femoris } \\
\text { artery (PFA) }\end{array}$ & $\begin{array}{l}\text { Medial circumflex } \\
\text { femoral artery (MCFA) }\end{array}$ & $\begin{array}{l}\text { Lateral circumflex femoral } \\
\text { artery (LCFA) }\end{array}$ & P value \\
\hline Postero- lateral & $60 \%$ & $65 \%$ & $80 \%$ & 0.05 \\
\hline Posterior & $30 \%$ & $15 \%$ & $15 \%$ & 0.01 \\
\hline Lateral & $5 \%$ & $12 \%$ & $5 \%$ & 0.04 \\
\hline Absent & $5 \%$ & $8 \%$ & $0 \%$ & 0.09 \\
\hline
\end{tabular}




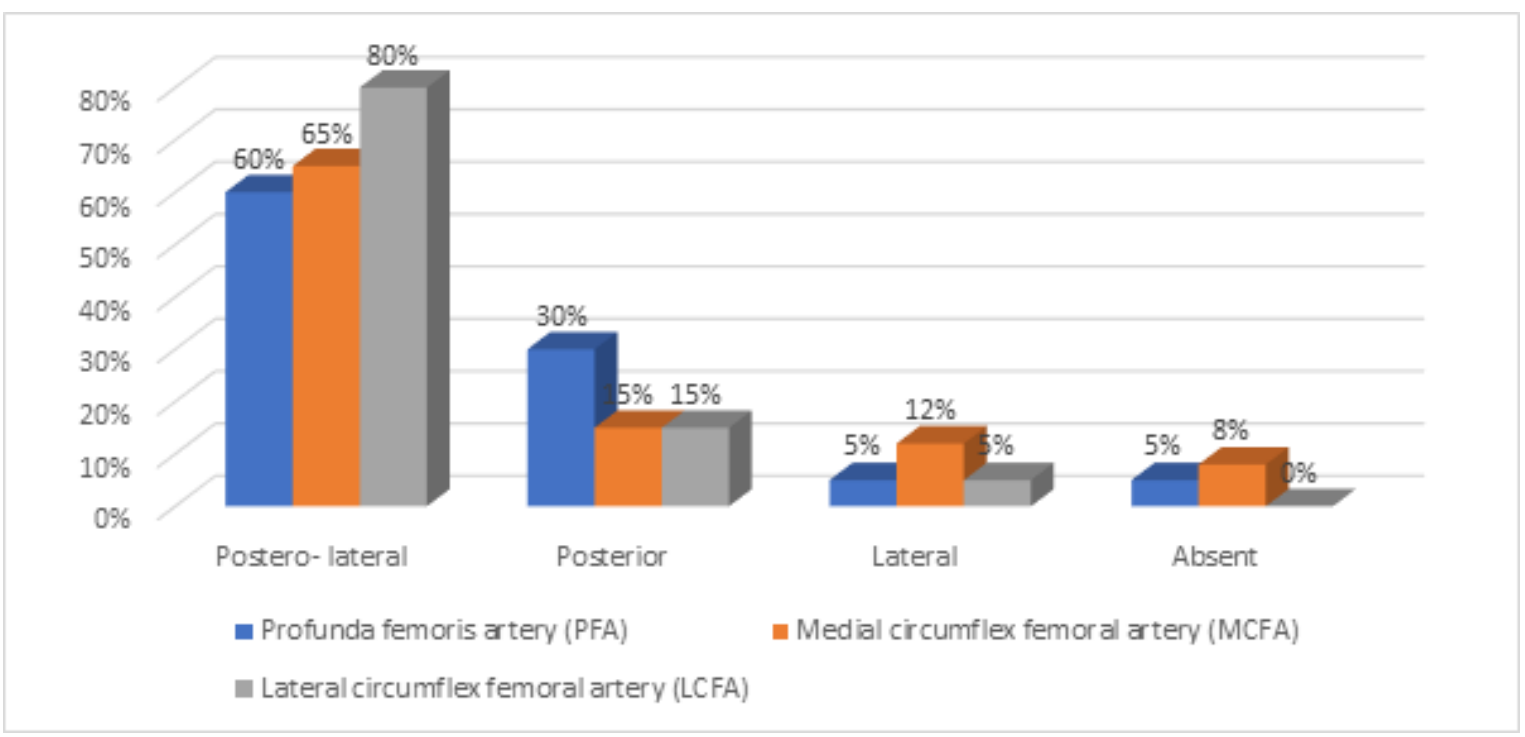

Figure 1:

Table 2: Origin of various arteries.

\begin{tabular}{|l|l|l|l|l|l|l|}
\hline Origin & $\begin{array}{l}\text { Profunda } \\
\text { femoris } \\
\text { artery (PFA) }\end{array}$ & $\begin{array}{l}\text { Medial } \\
\text { circumflex } \\
\text { femoral artery } \\
\text { (MCFA) }\end{array}$ & $\begin{array}{l}\text { Lateral } \\
\text { circumflex } \\
\text { femoral artery } \\
\text { (LCFA) }\end{array}$ & P value \\
\hline Femoris artery & $90 \%$ & FA & $55 \%$ & FA & $70 \%$ & 0.02 \\
\hline $\begin{array}{l}\text { Common Trunk } \\
\text { with MCFA }\end{array}$ & $10 \%$ & PFA & $40 \%$ & PFA & $20 \%$ & 0.05 \\
\hline- & $0 \%$ & $\begin{array}{l}\text { FA with } \\
\text { common } \\
\text { trunk with } \\
\text { MCFA }\end{array}$ & $5 \%$ & $\begin{array}{l}\text { FA with } \\
\text { common } \\
\text { trunk with } \\
\text { PFA }\end{array}$ & $10 \%$ & 0.15 \\
\hline
\end{tabular}

\section{DISCUSSION}

The lateral circumflex femoral artery (LCFA) is an artery that branches from the profunda femoris artery (PFA) and at times directly from the superficial femoral artery (SFA). [12,13] The LCFA is known for contributing to the blood supply of the muscles in the lateral aspect/compartment of the thigh, and to a lesser degree contributes to the blood supply of the neck of the femur and femoral head.[14] Around the shaft of the femur, the LCFA encircles the superior part of the femoral shaft and anastomoses with the medial circumflex artery of the thigh (MCFA). In its course, the LCFA passes laterally deep to the sartorius and rectus femoris muscles, dividing into the ascending, transverse and descending arteries. [15] The ascending branch supplies the anterior part of the gluteal region, transverse 
Annals of International Medical and Dental Research

E-ISSN: 2395-2822 | P-ISSN: 2395-2814

Vol-8, Issue-1 | January-February 2022

DOI: $10.53339 /$ aimdr.2022.8.1.24

Page no- 180-184 | Section- Research Article (Anatomy)

branch winds around the femur, while the descending branch joins genicular periarticular anastomosis. Therefore, the LCFA gives blood supply to the head and neck of the femur, greater trochanter, the vastus lateralis and the knee.[16,17] The present study was conducted to assess anatomical variations of profunda femoris artery in Indian population.

In our study, side of profunda femoris artery (PFA) was postero - lateral in $60 \%$, posterior in $30 \%$, lateral in 5\% and absent in 5\%. Medial circumflex femoral artery (MCFA) had 65\%, $15 \%, 12 \%$ and $8 \%$ and lateral circumflex femoral artery (LCFA) had $80 \%, 15 \%, 5 \%$ and $0 \%$ respectively. Mogale et al,[18] consisted of 55 cadavers of different ages, ancestry groups and varying body mass index. A total of 90 legs were dissected. The anterior thigh compartment was dissected and the common femoral artery (CFA), superficial femoral artery (SFA), PFA and LCFA further exposed. The course and variations were noted and results documented for further analysis. The LCFA was present in all the legs dissected. The origin of the LCFA was found to be the PFA in $75.6 \%$ of the left legs and $82.2 \%$ of the right legs dissected. In two cases, a male and female limb, the branching of the PFA from the CFA was observed directly from the external iliac artery, deep to the inguinal ligament. A variation was noted in a female cadaver, where the branches of the LCFA on the left limb had different points of origin. Another variation was noted on a male cadaver, the left limb had two different points of branching for the ascending and descending branches of the LCFA, a common trunk was absent.

We observed that origin of profunda femoris artery (PFA) was FA in $90 \%$ and common trunk with medial circumflex femoral artery in $10 \%$. Origin of Medial circumflex femoral artery (MCFA) was FA in 55\%, PFA in $40 \%$ and FA with common trunk with MCFA in 5\%. Origin of lateral circumflex femoral artery (LCFA) was femoral artery in $70 \%$, PFA in $20 \%$ and FA with common trunk with PFA in $10 \%$. Tzouma et al,[19] concluded that the DFA arises from the CFA with a varying site of origin, the posterolateral being the prevalent one found in $51.32 \%$ of cases. Of all cases studied, the MCFA and the LCFA most often originated from the DFA in $63.125 \%$ and $74.92 \%$, respectively, but the CFA constitutes another frequent source of origin in $27 \%$ and $12.12 \%$ of cases, respectively. The descending branch of the lateral circumflex femoral artery (dLCFA) is the prominent pedicle in the ALT flap, originating from the LCFA in $83.55 \%$ of cases. However, the presence of an oblique lateral circumflex femoral artery (oLCFA) branch with changeable origination was observed. Knowledge of the anatomical variants in the deep femoral artery is imperative both for interventional radiologists and surgeons. Especially in reconstructive surgery, the possibility for different sources supplying the skin and the pedicle compel surgeons to acquire an awareness of this subject. Also it is important to bear in mind the proximity of the femoral nerve, which lies just lateral to the artery.

\section{CONCLUSIONS}

A thorough knowledge of variation of profunda femoral artery is of great importance in diagnosing, therapeutic purposes. Points of origins are helpful to avoid high or low punctures. 
Annals of International Medical and Dental Research

E-ISSN: 2395-2822 | P-ISSN: 2395-2814

Vol-8, Issue-1 | January-February 2022

DOI: 10.53339/aimdr.2022.8.1.24

Page no- 180-184 | Section- Research Article (Anatomy)

\section{REFERENCES}

1. Manjappa T, Prasanna LC. Anatomical variations of the profunda femoris artery and its branches-a cadaveric study in South Indian population. Indian J Surg. 2014;76(4):288-292. doi:10.1007/s12262-0120677-3

2. Valdatta L, Tuinder S, Buoro M, Thione A, Faga A, Putz R. Lateral circumflex femoral arterial system and perforators of the anterolateral thigh flap: an anatomic study. Ann Plast Surg. 2002;49(2):145-50. doi: 10.1097/00000637-200208000-00006.

3. Gradman WS. Bypass to the lateral circumflex femoral artery. Ann Vasc Surg. 1992;6(4):344-6. doi: 10.1007/BF02008791.

4. Goel S, Arora J, Mehta V, Sharma M, Suri RK, Rath G. Unusual disposition of lateral circumflex femoral artery: Anatomical description and clinical implications. World J Clin Cases. 2015;3(1):85-88. doi:10.12998/wjcc.v3.i1.85

5. Fukuda H, Ashida M, Ishii R, Abe S, Ibukuro K. Anatomical variants of the lateral femoral circumflex artery: an angiographic study. Surg Radiol Anat. 2005;27(3):260-4. doi: 10.1007/s00276004-0312-5.

6. Başkaya MK, Kiehn MW, Ahmed AS, Ateş O, Niemann DB. Alternative vascular graft for extracranial-intracranial bypass surgery: descending branch of the lateral circumflex femoral artery. Neurosurg Focus. 2008;24(2):E8. doi: 10.3171/FOC/2008/24/2/E8.

7. Gaiotto FA, Vianna CB, Busnardo FF, Parga JR, Dallan LA, Cesar LA,. The descending branch of the lateral femoral circumflex artery is a good option in CABG with arterial grafts. Rev Bras Cir Cardiovasc. 2013;28(3):317-24. doi: 10.5935/1678-9741.20130050.

8. De Beer PM. The profunda femoris and circumflex femoral arteries in the South African Bantuspeaking Negro. S Afr J Med Sci. 1965;30(1):1-10.

9. Uzel M, Tanyeli E, Yildirim M. An anatomical study of the origins of the lateral circumflex femoral artery in the Turkish population. Folia Morphol (Warsz). 2008;67(4):226-30.

10. Sinkeet SR, Ogeng'o JA, Elbusaidy H, Olabu BO, Irungu MW. Variant origin of the lateral circumflex femoral artery in a black Kenyan population. Folia Morphol (Warsz). 2012;71(1):15-8.
11. Trousdale RT. Anterior surgical approaches for hip arthroplasty. Semin Artho. 2004;15:76-78.

12. Bal B. From two incisions to one: the technique of minimally invasive total hip arthroplasty with the anterior approach, Semin. Arthroplasty. 2008;19:215-224.

http://dx.doi.org/10.1053/j.sart.2008.02.011.

13. Marcus AJ, Lotzof K, Howard A. Access to the superficial femoral artery in the presence of a "hostile groin": a prospective study. Cardiovasc Intervent Radiol. 2007;30(3):351-4. doi: 10.1007/s00270-005-0347-y.

14. Perera J. Anatomy of the origin of the deep femoral artery. Ceylon Med J. 1995;40(4):139-41.

15. Massoud TF, Fletcher EW. Anatomical variants of the profunda femoris artery: an angiographic study. Surg Radiol Anat. 1997;19(2):99-103. doi: 10.1007/BF01628133.

16. Choi SW, Park JY, Hur MS, Park HD, Kang HJ, Hu KS, Kim HJ. An anatomic assessment on perforators of the lateral circumflex femoral artery for anterolateral thigh flap. J Craniofac Surg. 2007;18(4):866-71.

doi: 10.1097/scs.0b013e3180a03304.

17. Tansatit T, Wanidchaphloi S, Sanguansit P. The anatomy of the lateral circumflex femoral artery in anterolateral thigh flap. J Med Assoc Thai. 2008 Sep;91(9):1404-9.

18. Mogale N, Olorunju SA, Matshidza S, Briers N. Anatomical variations in the origins of the lateral circumflex femoral arteries in a South African sample: A cadaver study. Transl Res Anat. 2021;22:100098. https://doi.org/10.1016/j.tria.2020.100098

19. Tzouma G, Kopanakis NA, Tsakotos G, Skandalakis PN, Filippou D. Anatomic variations of the deep femoral artery and its branches: clinical implications on anterolateral thigh harvesting. $\begin{array}{lll}\text { Cureus. } & 2020 ; 12(4): & \end{array}$ https://doi.org/10.7759/cureus.7867

Source of Support: Nil, Conflict of Interest: None declared 